\title{
Dickkopf-1 Is Associated with Periarticular Bone Loss in Patients with Rheumatoid Arthritis
}

\author{
Berit Grandaunet $^{1 \#}$, Silje Watterdal Syversen ${ }^{2 \#}$, Mari Hoff ${ }^{3,4}$, Glenn Haugeberg ${ }^{3,5}$, \\ Désirée van der Heijde ${ }^{6}$, Tore K. Kvien ${ }^{2}$, Therese Standal ${ }^{1,7 \dagger}$
}

${ }^{1} \mathrm{KG}$ Jebsen Center for Myeloma Research and Department of Cancer Research and Molecular Medicine, Norwegian University of Science and Technology, Trondheim, Norway; ${ }^{2}$ Department of Rheumatology, Diakonhjemmet Hospital, Oslo, Norway; ${ }^{3}$ Department of Neuroscience, Norwegian University of Science and Technology, Trondheim, Norway; ${ }^{4}$ Department of Rheumatology, St. Olavs Hospital, Trondheim, Norway; ${ }^{5}$ Department of Rheumatology, Sørlandet Hospital, Kristiansand, Norway; ${ }^{6}$ Department of Rheumatology, Leiden University Medical Centre, Leiden, The Netherlands; ${ }^{7}$ Centre of Excellence for Molecular Inflammation Research, Trondheim, Norway.

Email: ${ }^{\dagger}$ therese.standal@ntnu.no

Received August $19^{\text {th }}, 2013$; revised September 19 $9^{\text {th }}, 2013$; accepted September $27^{\text {th }}, 2013$

Copyright (C) 2013 Berit Grandaunet et al. This is an open access article distributed under the Creative Commons Attribution License, which permits unrestricted use, distribution, and reproduction in any medium, provided the original work is properly cited.

\begin{abstract}
Objective: To examine whether cytokines shown to suppress osteoblasts, Dickkopf-1 (DKK1) and hepatocyte growth factor (HGF), are associated with periarticular bone loss in rheumatoid arthritis (RA). Methods: RA patients with short disease duration were prospectively followed and hand bone mineral density was assessed by digital X-ray radiogrammetry (DXR) at baseline and after 1, 2 and 5 years. Plasma samples collected at baseline from 136 of the included patients were analyzed for HGF and DKK1. Group comparisons, correlation analyses and multivariate analyses were performed to evaluate the relationship between baseline cytokine levels and DXR-BMD. Results: Patients with hand bone loss after 1 year had significantly higher baseline plasma levels of DKK1 than patients without bone loss. Patients with periarticular bone loss after 2 and 5 years had significantly higher baseline plasma levels of HGF. Baseline DKK1 but not HGF levels were independently associated with periarticular bone loss after 1 year. Conclusion: High serum levels of DKK1 are weakly but independently associated with periarticular bone loss in RA. The importance of DKK1 and HGF for loss of periarticular bone needs to be defined in future studies.
\end{abstract}

Keywords: Rheumatoid Arthritis; Osteoporosis; Osteoblast; DKK1; HGF

\section{Introduction}

Bone loss presents as focal joint erosions, periarticular bone loss and generalized osteoporosis in rheumatoid arthritis (RA). Periarticular bone loss occurs within the bone adjacent to inflamed joints and has been shown to precede and predict development of erosions [1]. Inflam-

\footnotetext{
*Competing interests: No competing interests to declare.

Funding: This study was supported by the Norwegian Research Council, Central Norway Regional Health Authority and the Norwegian Cancer Society.

Author's contributions: BG and SS acquired analysed and interpreted data and wrote the paper. $\mathrm{MH}, \mathrm{GH}, \mathrm{AS}, \mathrm{DvdH}$ interpreted data and contributed to writing of the paper. TK designed the study, interpreted data and wrote the paper. TS designed the study, acquired and interpreted data and wrote the paper. All authors were involved in drafting the article or revising it critically for intellectual content.

\#These two authors shared the first authorship.

${ }^{\dagger}$ Corresponding authors.
}

matory cytokines involved in osteoclast differentiation and activation is thought to be the dominant mechanism behind the development of both erosions and periarticular bone loss [2]. Recent data, however, suggest that osteoblasts and their precursors are also influenced by RA inflammation, hypothesizing that lack of bone repair contribute to the development of erosions [3-5].

Osteoblast dysfunction in relation to the development of periarticular bone loss has not been thoroughly studied. Central signaling pathways in osteoblast differentiation are the wingless (Wnt)-signaling pathway and the bone morphogenetic protein (BMP) pathway. Inhibitors of these pathways, Dickkopf-1 (DKK1) and hepatocyte growth factor (HGF), respectively, inhibit osteoblast differentiation and are associated with bone destruction in RA and multiple myeloma [4-8].

Periarticular bone loss is assessed with digital X-ray 
radiogrammetry (DXR) [1], whereas presence of focal erosions is commonly evaluated by scoring radiographs according to the Sharp Heijde method [9]. In a previous study on the same cohort we found that plasma level of HGF, but not DKK1, was an independent predictor of radiographic damage of joints both at short- and long-term follow-up [10]. In the present study we wanted to investigate if DKK1 and HGF were associated with periarticular hand bone loss assessed by DXR in RA.

\section{Materials and Methods}

\subsection{Patients}

The patients were recruited from the European Research on Incapacitating Disease and Social Support study (EURIDISS). The study enrolled 238 patients with RA of less than four years disease duration in $1992[1,11,12]$. The study was performed in compliance with Helsinki declaration and approved by regional ethics committee (REK Sør-Øst, number 2009/1770a). All patients had given informed consent. Patients were assessed at baseline and after 1, 2, 5 and 10 years. In total, 136 patients had both radiographs available for the 5-year follow-up and plasma samples stored at baseline. There were no significant differences between baseline characteristics of RA patients with or without available data (Table 1).

\subsection{Plasma Samples and Laboratory Analyses}

Samples were obtained at enrolment and stored at $-70^{\circ} \mathrm{C}$ with no freezing and thawing. Levels of HGF, DKK1, Anti-CCP, rheumatoid factor (RF), C-reactive protein (CRP) and erythrocyte sedimentation rate (ESR) were measured as previously described $[10,13]$.

Table 1. Baseline characteristics of the study population and the excluded patients in the cohort.

\begin{tabular}{ccc}
\hline & $\begin{array}{c}\text { Included patients } \\
\mathrm{N}=136\end{array}$ & $\begin{array}{c}\text { Excluded patients } \\
\mathrm{N}=102\end{array}$ \\
\hline Female \% & 76 & 71 \\
$\begin{array}{c}\text { Disease duration } \\
\text { mean } \pm \text { SD years }\end{array}$ & $2.2 \pm 1.2$ & $2.4 \pm 1.1$ \\
Age mean \pm SD years & $51.3 \pm 12.1$ & $52.8 \pm 14.2$ \\
Anti CCP positive, \% & 62 & 59 \\
RF IgM positive, \% & 48 & 48 \\
Steroid treatment, \% & 26 & 29 \\
$\begin{array}{c}\text { DMARD treatment, \% } \\
\text { CRP, mean } \pm \text { SD mg/L }\end{array}$ & 54 & 49 \\
$\begin{array}{c}\text { ESR, mean } \pm \\
\text { SD mm/hour }\end{array}$ & $26.2 \pm 20.8$ & $25.5 \pm 18.3$ \\
Baseline vdHeijde Sharp \\
score, median (IQR)
\end{tabular}

\subsection{Radiographs and DXR-BMD}

Conventional hand radiographs were analyzed with the DXR Pronosco X-posure system, V. 2.0 (Sectra, Linköping, Sweden). DXR-BMD was calculated based on hand radiographs taken at baseline and after 1,2 and 5 years of observation. Least significant change (LSC) was used as a cut-off to define loss in DXR-BMD exceeding the measurement error on the individual level and calculated as previously reported [1].

\subsection{Statistics}

Statistical analyses were performed using SPSS19 (IBMSPSS, Chicago, Illinois, USA).

Variables were selected for multivariate analyses based on previous studies on the EURIDISS material and known prognostic factors for radiographic progression in RA: Baseline DXR BMD, gender, CRP, ESR, age at inclusion, disease duration, anti-CCP positivity, RF IgM positivity, current DMARD and corticosteroid dose. The factors with a p-value $<0.15$ in univariate analyses were included in multivariate analyses.

\section{Results}

\subsection{Radiographic Results}

Mean (SD) DXR BMD was $0.547(0.088)$ at baseline, $0.532(0.092)$ at one year, $0.522(0.092)$ at two years, and $0.508(0.098)$ at 5 years' follow-up. The proportion of patients with DXR hand bone loss exceeding LSC was $67 \%$ at 1 year, $79 \%$ at 2 years and $89 \%$ after 5 years.

\subsection{Associations between HGF and DKK1 Levels and Baseline Characteristics}

The median baseline levels of HGF and DKK1 were 723 $\mathrm{pg} / \mathrm{mL}$ (interquartile range (IQR) 255) and $1575 \mathrm{pg} / \mathrm{mL}$ (IQR 3230), respectively.

HGF levels at baseline were positively correlated to age (rho 0.50, p < 0.001) and markers of inflammation (CRP, rho 0.21, p < 0.05, ESR, rho 0.39, p < 0.001) whereas DKK1 levels did not correlate to these parameters. There was a slightly higher median HGF level in the anti-CCP positive group $(742.0 \mathrm{pg} / \mathrm{mL}$, IQR $282.5, \mathrm{p}<$ $0.05)$ compared with the anti-CCP negative group (668.5 $\mathrm{pg} / \mathrm{mL}, \mathrm{IQR} 240$ ) but no difference in the baseline DKK1 level comparing these two groups.

\subsection{Higher Levels of DKK1 in Patients Developing Periarticular Osteoporosis}

DKK1 plasma levels at baseline were significantly higher (2010 pg/mL, IQR 3086) in patients developing periarticular bone loss after 1 year compared with patients without periarticular bone loss (1332.2 pg/mL, IQR 2094, p = 
$0.03)$, but this difference was not present at 2- and 5years follow up $(2104.9 \mathrm{pg} / \mathrm{mL}$, IQR 3062.5 vs 1790.4 $\mathrm{pg} / \mathrm{mL}, \mathrm{IQR} 2782, \mathrm{p}=0.4$ and $2087.1 \mathrm{pg} / \mathrm{mL}, \mathrm{IQR}$ 3084.9 vs $1105.8 \mathrm{pg} / \mathrm{mL}, \mathrm{IQR} 1885.9, \mathrm{p}=0.13$, respectively).

\subsection{Higher Levels of HGF in Patients Developing Periarticular Osteoporosis}

Baseline HGF levels were borderline significantly higher in the group of patients who developed periarticular bone loss compared with patients who did not after one-year follow up (769 pg/mL, IQR 277 vs. $653 \mathrm{pg} / \mathrm{mL}$, IQR 229, $\mathrm{p}=0.056)$ and significantly higher in the group of patients who developed periarticular bone loss after 2 years (752 pg/mL, IQR 284) and 5 years (737 pg/mL, IQR 271) compared with patients who did not $(676 \mathrm{pg} / \mathrm{mL}, \mathrm{IQR}$ 199 and $622 \mathrm{pg} / \mathrm{mL}$, IQR 303, p $=0.038, \mathrm{p}=0.045$, respectively).

\subsection{Associations between Cytokine Levels and Prospective Bone Loss}

Levels of HGF were associated with percentage bone loss at 1,2 and 5 years $(p=0.001, p=0.001, p=0.005)$. Levels of DKK1 were significantly associated with percentage bone loss at 1 -year observation $(p=0.013)$, but not after 2 years $(p=0.094)$ or $5(p=0.714)$ (Table 2$)$.

In multivariate regression analyses levels of DKK1 were found to be significantly associated with percentage bone loss at 1-year observation as were also CRP, ESR, and anti-CCP (Table 3). Baseline plasma levels of DKK1 were not associated with percentage bone loss after 2 and 5 years $(\beta: 0.105, \mathrm{p}=0.193, \beta: 0.01, \mathrm{p}=$ 0.907 , respectively).

HGF was not associated with percentage bone loss in multivariate regression models at any time point (1 year:

Table 2. Associations with baseline plasma levels of cytokines and percentage bone loss.

\begin{tabular}{cccc}
\hline \multirow{2}{*}{$\begin{array}{c}\text { Baseline cytokine } \\
\text { levels }\end{array}$} & Standardized $\beta$ & $\mathrm{R}^{2}$ & p-value \\
\cline { 2 - 3 } DKK1 pg/mL & Percentage bone loss after 1 year observation \\
\hline HGF pg/mL & 0.214 & 0.046 & 0.013 \\
& 0.285 & 0.081 & 0.001 \\
DKK1 pg/mL & 0.148 & 0.022 & 0.094 \\
HGF pg/mL & 0.298 & 0.089 & 0.001 \\
& & & \\
& Percentage bone loss after 5 years observation \\
DKK1 pg/mL & 0.034 & 0.001 & 0.714 \\
HGF pg/mL & 0.255 & 0.065 & 0.005 \\
\hline
\end{tabular}

Table 3. Baseline predictors of percentage bone loss after 1year observation.

\begin{tabular}{cccc}
\hline & $\beta$ & $\mathrm{p}$ & $\begin{array}{c}\mathrm{R}^{2} \text { combined } \\
\text { regression model }\end{array}$ \\
\hline CRP & -0.280 & 0.008 & \\
ESR & 0.597 & $<0.001$ & 0.355 \\
Anti-CCP positive & 0.232 & 0.008 & \\
DKK1 & 0.178 & 0.022 & \\
\hline
\end{tabular}

$\beta: 0.092, \mathrm{p}=0.319,2$ year. $\beta: 0.080, \mathrm{p}=0.405,5$ year. $\beta$ : $0.083, \mathrm{p}=0.400$ ).

\section{Discussion}

The main finding in this study is that high plasma levels of DKK1 at baseline are independently associated with short-term loss of periarticular bone-mass assessed by DXR-BMD. These findings support that, as for the development of focal erosions, osteoblast suppression may play a role in the development of periarticular bone loss.

In a previous study from the same cohort we found that levels of DKK1 at baseline were not associated with development of focal erosions assessed by Sharp Heijde score [10], while we here found DKK1 to weakly but independently predict periarticular bone loss at 1-year follow up. Even though such a conclusion cannot be made based on the present study, this raises the hypothesis of an even more important role for DKK1 in development of periarticular bone loss as compared to development of erosions.

Levels of HGF, on the other hand, was shown to be an independent predictor of radiographic damage of joints both at short- and long-term follow-up [10], but was not associated with periarticular bone loss in adjusted analyses at any time point. Although we and others have shown that HGF inhibits osteoblast differentiation [6,7] it seems clear that the effect of HGF on osteoblast differentiation is dependent on the concentration of the cytokine, and that HGF at low concentrations in fact may promote rather than inhibit osteoblastogenesis [14]. Plasma levels of HGF correlate to levels of HGF in synovial fluid, and levels of HGF are higher in synovial fluid than in serum obtained simultaneously from the same individuals $[15,16]$. Hence, HGF at high concentrations in the joints are more likely to act negatively on osteoblasts than HGF at the lower concentrations found in circulation. On the other hand, lack of an independent association of HGF with periarticular bone loss might also be due to confounding or methodological issues.

There are several important limitations to this study. First of all, the observed associations are rather weak and need to be confirmed in future studies. It is not possible 
to draw conclusions regarding mechanisms for pathophysiologic processes based on plasma levels of cytokines.

Periarticular bone loss was determined by examination of radiographs of the hands only, while cytokine levels measured in the circulation probably reflect the degree of inflammation and destruction in several joints. Preanalysis sources of variation (different treatment regimens, diurnal variation, comorbidity) as well as possible effects of sampling and storage can affect plasma levels of cytokines and must be taken into account in the interpretation of the data. Another important limitation is the small group of patients $(n=13)$ that were classified as not having a significant loss in DXR BMD at 5 years observation. Thus the group is probably too small to reveal any association between the measured cytokines and hand bone loss in a long-term perspective.

\section{Conclusion}

Our data suggest an independent association of plasma levels of DKK1 and loss of periarticular bone in RA. The relative importance of DKK1 and HGF in terms of loss of periarticular bone compared with development of erosions needs to be explored in future studies.

\section{Acknowledgements}

We thank Berit Størdal for technical assistance.

\section{REFERENCES}

[1] M. Hoff, G. Haugeberg, S. Odegard, S. Syversen, R. Landewe, H. D. van der and T. K. Kvien, "Cortical Hand Bone Loss after 1 Year in Early Rheumatoid Arthritis Predicts Radiographic Hand Joint Damage at 5-Year and 10-Year Follow-Up," Annals of the Rheumatic Diseases, Vol. 68, No. 3, 2009, pp. 324-329.

http://dx.doi.org/10.1136/ard.2007.085985

[2] G. Schett, "Cells of the Synovium in Rheumatoid Arthritis. Osteoclasts," Arthritis Research \& Therapy, Vol. 9, No. 1, 2007, p. 203. http://dx.doi.org/10.1186/ar2110

[3] N. C. Walsh and E. M. Gravallese, "Bone Remodeling in Rheumatic Disease: A Question of Balance," Immunological Reviews, Vol. 233, No. 1, 2010, pp. 301-312. http://dx.doi.org/10.1111/j.0105-2896.2009.00857.x

[4] D. Diarra, M. Stolina, K. Polzer, J. Zwerina, M. S. Ominsky, D. Dwyer, A. Korb, J. Smolen, M. Hoffmann, C. Scheinecker, H. D. van der, R. Landewe, D. Lacey, W. G. Richards and G. Schett, "Dickkopf-1 Is a Master Regulator of Joint Remodeling," Nature Medicine, Vol. 13, No. 2, 2007, pp. 156-163. http://dx.doi.org/10.1038/nm1538

[5] M. M. Matzelle, M. A. Gallant, K. W. Condon, N. C. Walsh, C. A. Manning, G. S. Stein, J. B. Lian, D. B. Burr and E. M. Gravallese, "Resolution of Inflammation Induces Osteoblast Function and Regulates the Wnt Signaling Pathway," Arthritis and Rheumatism, 2011.
[6] T. Standal, N. Abildgaard, U. M. Fagerli, B. Stordal, O. Hjertner, M. Borset and A. Sundan, "HGF Inhibits BMPInduced Osteoblastogenesis: Possible Implications for the Bone Disease of Multiple Myeloma," Blood, Vol. 109, No. 7, 2007, pp. 3024-3030.

[7] T. Kawasaki, Y. Niki, T. Miyamoto, K. Horiuchi, M. Matsumoto, M. Aizawa and Y. Toyama, "The Effect of Timing in the Administration of Hepatocyte Growth Factor to Modulate BMP-2-Induced Osteoblast Differentiation," Biomaterials, Vol. 31, No. 6, 2010, pp. 1191-1198. http://dx.doi.org/10.1016/j.biomaterials.2009.10.048

[8] E. Tian, F. Zhan, R. Walker, E. Rasmussen, Y. Ma, B. Barlogie and J. D. Shaughnessy Jr., "The Role of the Wnt-Signaling Antagonist DKK1 in the Development of Osteolytic Lesions in Multiple Myeloma," New England Journal of Medicine, Vol. 349, No. 26, 2003, pp. 24832494. http://dx.doi.org/10.1056/NEJMoa030847

[9] D. M. van der Heijde, "Radiographic Imaging: The 'Gold Standard' for Assessment of Disease Progression in Rheumatoid Arthritis," Rheumatology, Vol. 39, No. S1, 2000, pp. 9-16.

http://dx.doi.org/10.1093/oxfordjournals.rheumatology.a0 $\underline{31496}$

[10] B. Grandaunet, S. W. Syversen, M. Hoff, A. Sundan, G. Haugeberg, H. D. van der, T. K. Kvien and T. Standal, "Association between High Plasma Levels of Hepatocyte Growth Factor and Progression of Radiographic Damage in the Joints of Patients with Rheumatoid Arthritis," Arthritis and Rheumatism, Vol. 63, No. 3, 2011, pp. 662669. http://dx.doi.org/10.1002/art.30163

[11] L. M. Smedstad, T. K. Kvien, T. Moum and P. Vaglum, "Life Events, Psychosocial Factors, and Demographic Variables in Early Rheumatoid Arthritis: Relations to OneYear Changes in Functional Disability," Journal of Rheumatology, Vol. 22, No. 12, 1995, pp. 2218-2225.

[12] F. C. Arnett, S. M. Edworthy, D. A. Bloch, D. J. McShane, J. F. Fries, N. S. Cooper, L. A. Healey, S. R. Kaplan, M. H. Liang, H. S. Luthra, et al., "The American Rheumatism Association 1987 Revised Criteria for the Classification of Rheumatoid Arthritis," Arthritis and Rheumatism, Vol. 31, No. 3, 1988, pp. 315-324. http://dx.doi.org/10.1002/art.1780310302

[13] S. W. Syversen, P. I. Gaarder, G. L. Goll, S. Odegard, E. A. Haavardsholm, P. Mowinckel, D. van der Heijde, R. Landewe and T. K. Kvien, "High Anti-Cyclic Citrullinated Peptide Levels and an Algorithm of Four Variables Predict Radiographic Progression in Patients with Rheumatoid Arthritis: Results from a 10-Year Longitudinal Study," Annals of the Rheumatic Diseases, Vol. 67, No. 2, 2008, pp. 212-217. http://dx.doi.org/10.1136/ard.2006.068247

[14] Q. Wen, L. Zhou, C. Zhou, M. Zhou, W. Luo and L. Ma, "Change in Hepatocyte Growth Factor Concentration Promote Mesenchymal Stem Cell-Mediated Osteogenic Regeneration," Journal of Cellular and Molecular Medicine, 2011.

[15] K. Yukioka, M. Inaba, Y. Furumitsu, M. Yukioka, T. Nishino, H. Goto, Y. Nishizawa and H. Morii, "Levels of Hepatocyte Growth Factor in Synovial Fluid and Serum 
of Patients with Rheumatoid Arthritis and Release of Hepatocyte Growth Factor by Rheumatoid Synovial Fluid Cells," Journal of Rheumatology, Vol. 21, No. 12, 1994, pp. 2184-2189.

[16] A. E. Koch, M. M. Halloran, S. Hosaka, M. R. Shah, C. J. Haskell, S. K. Baker, R. J. Panos, G. K. Haines, G. L. Ben- nett, R. M. Pope and N. Ferrara, "Hepatocyte Growth Factor. A Cytokine Mediating Endothelial Migration in Inflammatory Arthritis," Arthritis and Rheumatism, Vol. 39, No. 9, 1996, pp. 1566-1575.

http://dx.doi.org/10.1002/art.1780390917 